\title{
Editorial
}

\section{El desarrollo sostenible y la COP25}

Éste año Chile será sede la vigésimo quinta versión Conferencia de las Partes (COP). Esta conferencia, es el órgano de decisión supremo de la Convención Marco de las Naciones Unidas frente al Cambio Climático, la cual está compuesta por 196 países miembros más la Unión Europea. Los miembros de la COP se reúnen anualmente y es la mayor cumbre que se realiza a nivel mundial para abordar las acciones globales frente al cambio climático.

Uno de los conceptos y ejes temáticos que promueve esta conferencia es el desarrollo sostenible, el cual se define como un modelo basado en tres factores: el económico, el social y el medioambiental, que apunta a una armonía entre el bienestar económico, el respeto a los derechos humanos y la conservación del medio ambiente.

Esta conferencia llega al país en un momento de crisis ambiental tanto a nivel nacional como regional. Esta crisis da cuenta de la alerta ecológica producida por la contaminación atmosférica en varias ciudades del país, Santiago, Valdivia y Temuco; la desertificación producida por la sequía que afecta a varias regiones nortinas; la contaminación del borde costero producida por los desechos químicos; las malas prácticas en la empresas salmonicultura y pesca artesanal que afecta a las costas del litoral y los desechos pláticos de los océanos, por nombrar algunos. Por lo que el tema se ha instalado en el escenario público y el debate entre el sector ambientalista versus el empresarial se aprecia extremadamente polarizado e ideologizado.

Por lo que es primordial comprender que el desarrollo sostenible es el camino hacia el futuro. Pero éste no se podrá consolidar al interior de los estados sino mediante un marco de tolerancia, respeto de todos los actores sociales. También es fundamental comprender que todas las actividades humanas causan algún nivel de impacto ambiental pero que todas -en su sustentable medida- son necesarias para la subsistencia de la población humana en este planeta. Por lo que es esperable que la COP25 ayude a allanar las diferencias entre las partes debatientes y consolidar el desarrollo sostenible como el eje de la gobernanza de los países.

Dr. Américo Montiel San Martin 
